\title{
BM Global Heatth Public health impact of the 2014-2015 Ebola outbreak in West Africa: seizing opportunities for the future
}

\author{
Alexandre Delamou, ${ }^{1}$ Thérèse Delvaux, ${ }^{2}$ Alison Marie El Ayadi, ${ }^{3}$ \\ Abdoul Habib Beavogui, ${ }^{4}$ Junko Okumura, ${ }^{5}$ Wim Van Damme, ${ }^{6}$ Vincent De Brouwere ${ }^{2}$
}

To cite: Delamou A, Delvaux T, El Ayadi AM, et al. Public health impact of the 2014-2015 Ebola outbreak in West Africa: seizing opportunities for the future. BMJ Global Health 2017;2: e000202. doi:10.1136/ bmjgh-2016-000202

Received 30 September 2016 Accepted 20 January 2017

CrossMark

For numbered affiliations see end of article.

Correspondence to Dr Alexandre Delamou; adelamou@gmail.com
The 2014-2015 Ebola virus disease (EVD) outbreak was unique in geography and extent, with most of the 28610 cases and 11308 deaths, including among healthcare workers (HCW), occurring in Guinea, Liberia and Sierra Leone. ${ }^{1}$ Explanations for the rapid spread and persistence of the outbreak include weak health systems (limited qualified HCW, poor infrastructure and logistics, and weak governance and funding for the health sector), sociocultural behaviours misaligned with infection control measures, poverty, political instability, poorly coordinated vertical programmes and significant cross-border population mobility. ${ }^{2}$

These realities hindered an effective and immediate response to the outbreak, resulting in the disastrous public health impacts observed in West Africa. Ill-implemented EVD control strategies and insufficient communication with the population led to a suspicion of 'Ebola business' that created mistrust in the health systems and their stewards. ${ }^{45}$ This resulted in communities' refusal to seek care for EVD-related symptoms and avoidance of health facilities. ${ }^{5}$ In Sierra Leone, for example, a $30 \%$ decreased odds of facility-based delivery were reported in rural areas after the start of the EVD outbreak. ${ }^{6}$ In Guinea, a rapid decrease in urban maternity admissions in Conakry was observed after the EVD outbreak started. ${ }^{7}$

The EVD outbreak has also led to the disruption in service use and an accompanying substantial increase in the mortality rates of other diseases such as malaria, HIV/AIDS and tuberculosis across West Africa. ${ }^{8}$ For example, Plucinski et at reported $11 \%$ and $15 \%$ reductions in all-cause outpatient visits and cases of fever, respectively, in Guinea in 2014 compared with the period before Ebola, and estimated that the EVD outbreak resulted in 74000 (95\% CI 71000-77 000) fewer malaria cases countrywide seen at

\section{Summary box}

- The 2014-2015 Ebola virus disease outbreak resulted in devastating human, health and socioeconomic consequences in West African affected countries.

- The EVD outbreak brought several opportunities to West Africa by improving logistics, quality standards and developing local research and training capacities in affected countries.

- It also increased public awareness raising about health threats and commitment to health systems strengthening.

- Empowerment and capacity building at the community level are key to countries' preparedness to face future epidemics.

health facilities, suggesting that more cases of malaria were treated at home and therefore not well managed. The EVD outbreak has spurred health regulation reform in West Africa and beyond, resulting in a very tenuous balance between the need to reduce EVD transmission and important unintended social consequences.

Following the WHO's recommendations, ${ }^{10}$ West African countries systematically implemented exit screenings at borders and limited/ banned travel for suspected EVD cases. Outbreak control activities also led to the closure of schools, markets and hospitals, and some countries even closed borders for fear of mass transmission. Through outbreak control activities and spurred by fears of transmission, the EVD outbreak had a significant impact on the economy of the region, reducing agriculture and fishing, mainstays of the communities and severely curtailing business and trade activities. $^{11}$ Further public health deterioration operated through economic pathways, increasing poverty and food insecurity. ${ }^{12}$

However, despite these negative impacts on public health and beyond, the EVD outbreak has brought some opportunities to West African countries that must be highlighted 
and sustained. First, the devastating pace of EVD led to a paradigm change in West Africa. The EVD which was perceived as a 'simple' public health concern at the beginning, then rapidly became a threat to national security, social and political stability and economic growth. This paradigm change required aggressive public measures to mitigate its devastating impacts. For example, Guinea increased government spending on health, recruited 2950 additional HCW and began prioritising community participation in response to public health threats. ${ }^{13}$

These efforts should be sustained in the post-EVD phase and in addition to the existing, the additional HCW recruited in Guinea, including 320 doctors, 950 nurses, 500 midwives, 1010 assistant nurses and 170 paramedics, will require additional training to meet the healthcare challenges generated by the EVD outbreak. Second, West African countries have benefited substantially from external funding for EVD control and health systems strengthening activities. Thus, infection control skills, humanitarian logistics and disease surveillance capabilities have been improved. ${ }^{14}$ In addition, promising scientific collaborations for vaccine development and other clinical research activities have been developed. For example, the Partnership for Research on Ebola Virus Disease (PREVAIL II) trial which assessed the efficacy of ZMapp treatment in patients with EVD in West Africa involved Sub-Regional Consortium of researchers from Liberia, Sierra Leone and Guinea under the auspices of the National Institutes of Health (NIH) ${ }^{15}$

The follow-on project funded by the NIH and others, Partnership for Research on Ebola VACcination (PREVAC), with the aim to assess the antibody response of three vaccine strategies in the three EVD-affected countries will further foster the collaborative research partnership started during the EVD outbreak. This, in addition to other research initiatives conducted in the three countries, has substantially increased local research capacities, including infrastructure development, capacity strengthening, ethics and scientific productivity. ${ }^{14} 16$

Owing to the EVD outbreak, Guinea is now included within the priority countries of the Belgian Cooperation and a scientific collaboration between the Institute of Tropical Medicine of Antwerp and Guinea will begin soon (2017-2021). Opportunities for developing local postgraduate training programmes in public health in the most EVD affected countries are also becoming available. Third, the EVD outbreak has provided job opportunities to hundreds of young health professionals in search of their first working experience. Also, many nationals from the region have been deployed in the field to support international efforts to stop the outbreak and rebuild the health systems, bringing greater public interest and attention to public health.

Thus, the legacy of the 2014-2015 EVD outbreak in West Africa should not only be considered from a negative perspective, and, while efforts are needed to mitigate these impacts on health programmes and services, an emphasis should be put on the preparedness of West African countries most affected by the EVD to face future epidemics. Preparedness in the region, particularly Liberia, Sierra Leone and Guinea, entails that the capacity building efforts and the increased post-Ebola HCW employment result in continued population health improvements and a sustained health systems strengthening. Strengthened health systems require evidence-based policy reforms and adequate health planning and financing.

Only a strong focus on empowerment and capacity building at the community level, including targeted health education initiatives, will ensure community-level cooperation and result in sustained behavioural changes and community resilience. It is also urgent to learn from the EVD humanitarian assistance and rethink the humanitarian-researchers' collaboration. We believe that only stronger health systems and wider multisectorial collaboration will result in greater gains across all aspects of healthcare. To this end, West African countries should continue to document the complex effects of the EVD on the health system and health services and use the lessons learnt to inform policies and programmes.

\section{Author affiliations}

${ }^{1}$ Department of Public Health, Gamal University of Conakry, Conakry, Guinea ${ }^{2}$ Woman and Child Health Research Centre, Institute of Tropical Medicine, Antwerp, Belgium

${ }^{3}$ Bixby Center for Global Reproductive Health, University of California, San Francisco, California, USA

${ }^{4}$ Department of Parasitology-Mycology, Gamal University of Conakry, Conakry, Guinea

${ }^{5}$ Institute of Tropical Medicine, Nagasaki University, Nagasaki, Japan ${ }^{6}$ Health Policy Unit, Department of Public Health, Institute of Tropical Medicine, Antwerp, Belgium

Handling editor Seye Abimbola.

Competing interests None declared.

Provenance and peer review Not commissioned; externally peer reviewed.

Data sharing statement No additional data are available.

Open Access This is an Open Access article distributed in accordance with the Creative Commons Attribution Non Commercial (CC BY-NC 4.0) license, which permits others to distribute, remix, adapt, build upon this work noncommercially, and license their derivative works on different terms, provided the original work is properly cited and the use is non-commercial. See: http:// creativecommons.org/licenses/by-nc/4.0/

\section{REFERENCES}

1. World Health organization (WHO). Ebola situation report-30 March 2016. http://apps.who.int/ebola/current-situation/ ebola-situation-report-30-march-2016 (accessed 12 Sep 2016).

2. Cranmer H, Aschkenasy M, Wildes R, et al. Academic institutions' critical guidelines for health care workers who deploy to West Africa for the Ebola response and future crises. Disaster Med Public Health Prep 2015;9:586-90.

3. Kieny MP, Evans DB, Schmets G, et al. Health-system resilience: reflections on the Ebola crisis in western Africa. Bull World Health Organ 2014;92:850.

4. Thiam S, Delamou A, Camara S, et al. Challenges in controlling the Ebola outbreak in two prefectures in Guinea: why did communities continue to resist? Pan Afr Med J 2015;22(Suppl 1):22.

5. Elston JW, Moosa AJ, Moses F, et al. Impact of the Ebola outbreak on health systems and population health in Sierra Leone. J Public Health (Oxf) 2016;38:673-8. 
6. Ly J, Sathananthan V, Griffiths T, et al. Facility-based delivery during the Ebola virus disease epidemic in rural Liberia: analysis from a cross-sectional, population-based household survey. PLOS Med 2016;13:e1002096.

7. Delamou A, Hammonds RM, Caluwaerts S, et al. Ebola in Africa: beyond epidemics, reproductive health in crisis. Lancet 2014;384:2105.

8. Parpia AS, Ndeffo-Mbah ML, Wenzel NS, et al. Effects of response to 2014-2015 Ebola outbreak on deaths from Malaria, HIV/AIDS, and tuberculosis, West Africa. Emerging Infect Dis 2016;22: 433-41.

9. Plucinski MM, Guilavogui T, Sidikiba S, et al. Effect of the Ebola-virus-disease epidemic on malaria case management in Guinea, 2014: a cross-sectional survey of health facilities. Lancet Infect Dis 2015;15:1017-23.

10. World Health organization (WHO). Statement on the 1st meeting of the IHR Emergency Committee on the 2014 Ebola outbreak in West Africa. WHO statement-8 August 2014. http://www.who.int/ mediacentre/news/statements/2014/ebola-20140808/en/ (accessed 13 Sep 2016).
11. Bowles J, Hjort J, Melvin T, et al. Ebola, jobs and economic activity in Liberia. J Epidemiol Community Health 2016;70:271-7.

12. United Nations Development Group (UNDG). Socio-Economic Impact of Ebola Virus Disease in West African Countries. A call for national and regional containment, recovery and prevention. http:// www.africa.undp.org/content/dam/rba/docs/Reports/ ebola-west-africa.pdf (accessed 9 Nov 2016)

13. Perry HB, Dhillon RS, Liu A, et al. Community health worker programmes after the 2013-2016 Ebola outbreak. Bull World Health Organ 2016;94:551-3.

14. Cooper C, Fisher D, Gupta N, et al. Infection prevention and control of the Ebola outbreak in Liberia, 2014-2015: key challenges and successes. BMC Med 2016;14:2.

15. Davey RT Jr, Dodd L, Proschan MA, et al., PREVAIL II Writing Group, Multi-National PREVAIL II Study Team. A randomized, controlled trial of ZMapp for Ebola virus infection. N Engl J Med 2016;375:1448-56.

16. Beavogui AH, Delamou A, Yansane ML, et al. Clinical research during the Ebola virus disease outbreak in Guinea: lessons learned and ways forward. Clin Trials 2016;13:73-8. 